FEATURE ARTICLE

\title{
Survey of lesbian, gay, bisexual, and transgender people's experiences of mental health services in Ireland
}

\author{
Edward McCann and Danika Sharek \\ School of Nursing and Midwifery, Trinity College, University of Dublin, Dublin, Ireland
}

\begin{abstract}
Very little is known about the experiences of lesbian, gay, bisexual, and transgender (LGBT) people in relation to mental health services. Therefore, the overall aim of the current research was to explore LGBT people's experiences of mental health service provision in Ireland. The objectives were to identify barriers and opportunities, to highlight service gaps, and to identify good practice in addressing the mental health and well-being of LGBT people. A mixed methods research design using quantitative and qualitative approaches was deployed. A multipronged sampling strategy was used and 125 respondents responded to the questionnaire. A subset of phase $1(\mathrm{n}=20)$ were interviewed in the qualitative phase. Quantitative data was analyzed using descriptive statistics. Qualitative data were analyzed thematically. The sample consisted of LGBT people $(\mathrm{n}=125)$ over 18 years of age living in Ireland. Over three-quarters $(77 \%)$ had received a psychiatric diagnosis. Findings include that whilst $63 \%$ of respondents were able to be 'out' to practitioners, $64 \%$ felt that mental health professionals lacked knowledge about LGBT issues and 43\% felt practitioners were unresponsive to their needs. Finally, respondent recommendations about how mental health services may be more responsive to LGBT people's needs are presented.
\end{abstract}

KEY WORDS: bisexual, gay, lesbian, mental health services, transgender.

\section{BACKGROUND}

As with other marginalized groups in society, lesbian, gay, bisexual, and transgender (LGBT) people face discrimination, in schools, workplaces, and within the wider community (European Commission 2012; Meyer et al. 2007; Newcomb \& Mustanski 2010). Although being LGBT is no longer considered 'pathological', studies demonstrate that LGBT people experience more psychological distress than heterosexual people and are at greater risk of mental health problems (Burgess et al. 2008; King et al. 2008; Meyer 2010). A review of the international published work on the topic revealed studies conducted in the USA,

Correspondence: Edward McCann, Trinity College Dublin, School of Nursing and Midwifery, 24 D’Olier Street, Dublin 2, Ireland. Email: mccanned@tcd.ie

Edward McCann, PhD, MSc, RN, RPN, FHEA.

Danika Sharek, MSc.

Accepted February 2013.
Australia, Canada, and the UK. Some of the identified issues included institutionalized prejudice, social stress, social exclusion, homophobic and transphobic hatred, bullying, and violence (David \& Knight 2008; King \& Smith 2004; Kuyper \& Fokkema 2011). Furthermore, there can be an increased susceptibility to alcohol and drug misuse as well as suicidality and issues related to self-harm (Cochran et al. 2003; Grant et al. 2011). In terms of sexual orientation, while most gay, lesbian, and bisexual young people develop positive coping strategies to manage the ensuing stress and become healthy, resilient adults, mental health nurses should appreciate the relationship between sexual orientation or gender identity and mental distress in order to be in a position to identify vulnerable individuals and promote mental health among an already marginalized group of people (Chakraborty et al. 2011; King et al. 2003). In a study on suicide risk among transgender people $(n=153), 41 \%$ of transgender 
men and $20 \%$ of transgender women reported suicide attempts (Maguen \& Shipherd 2010). Within Ireland, Mayock et al. (2009) reported that $86 \%$ of the LGBT participants they surveyed experienced depression at some point in their lives, with $25 \%$ taking prescribed medication, and $27 \%$ indicating that they had self-harmed at least once in their lives. However, gaps in knowledge remain around the experiences of LGBT people and Irish mental health services despite recommendations by LGBT groups (National Gay and Lesbian Federation 2009) and statutory government bodies (Health Service Executive 2009). Furthermore, in terms of mental health, international policy initiatives and guidance documents highlight the need to develop holistic, seamless, socially inclusive, recovery-oriented services which foster active partnerships between service users and mental health practitioners (Australian Government 2010; Government of Ireland 2006; Government of Scotland 2006; Mental Health Commission 2008). Consequently, the focus is on a more responsive, empowering, and all-embracing mental health service that puts individuals, families, and carers at the core of mental health care (Happell 2008; Health Service Executive 2012).

The current study aimed to uncover the obstacles to full participation in mainstream mental health services for LGBT people and to explore the circumstances of exclusion in mental health services. Hopes and aspirations around LGBT people's mental health needs were explored. Furthermore, areas of good practice were highlighted that encourage social inclusion at all levels. Finally, recommendations were made as to how to respond to the key issues identified in the research as they relate to LGBT people and to contribute to the development of a national policy framework for LGBT people that promotes positive mental health, full participation, and inclusion in society. This paper reports on the findings related to the survey. The findings from the qualitative interviews are currently being prepared for publication.

\section{METHOD}

\section{Study aim and objectives}

The overall aim of the research was to explore LGBT people's experiences of mental health service provision in Ireland. The objectives of the study were to:

- Identify the positive and negative LGBT-related experiences of accessing and using mental health services

- Discover the barriers to, and opportunities for, LGBT people accessing and using mental health services and highlight service gaps
- Identify good practice in addressing the mental health and well-being of LGBT people

- Make recommendations in terms of mental health practice, policy, and research.

The approach used in the study was an exploratory design and the survey instrument could be completed electronically, by telephone, or by post.

\section{Sampling and inclusion criteria}

People were eligible to participate in the study if they were over 18 years of age, identified as LGBT, and had used mainstream mental health services in Ireland in the past 5 years. Convenience sampling was used as a recognized approach to increasing the response rate in socially excluded groups and hard-to-reach populations (Flanagan \& Hancock 2010; Hughes 2009).

In total, 156 questionnaires were returned. It is difficult to estimate how representative the sample is as no national data on LGBT identity has been collected to date. However, according to the 2011 Census, the total population of Ireland was 4581269 (Central Statistics Office 2011). It is estimated that approximately $5-7 \%$ of the population may be lesbian, gay, and bisexual (LGB), representing roughly 229063-320689 LGB people in Ireland (UK Department of Trade and Industry 2003). The size of the transsexual and transgender population in Ireland is unknown, but a recent report suggests that the prevalence of people with gender identity disorder in Ireland is consistent with international estimates (De Gascun et al. 2006). International data from the Netherlands estimates transsexual prevalence rates at approximately 1 in 11900 individuals assigned male (trans woman) over the age of 15 years and 1 in 30400 for individuals assigned female (trans man) over 15 years of age (Health Service Executive 2009).

\section{Survey design}

The principal investigator designed the survey in conjunction with the Research Advisory Group. The final survey consisted of 35 questions that were sourced from a number of previously developed instruments including the Supporting LGBT Lives questionnaire (Mayock et al. 2009), the Visible Lives questionnaire (Higgins et al. 2011), and the National Census of Ireland (Central Statistics Office 2006). The survey primarily consisted of closed-ended questions. These questions were grouped around a number of topics, including: demographic and relationship status; sexual orientation and gender identity; proportion of people who know the respondent is 'out'; mental health status and diagnoses; and mental health service use and experiences. There were also two 
open-ended questions on the survey asking respondents to make suggestions for improving mental health services for LGBT people in Ireland, as well as a space for any additional comments.

\section{Survey pilot}

In order to test the survey for content and face validity, a pilot survey was conducted with five respondents. These respondents were recruited from an LGBT organization in Dublin and all respondents fitted the inclusion criteria. Each respondent was asked to complete the survey and to provide feedback and suggestions in order to improve it. Respondents' feedback was mostly positive, describing the survey as useful and appropriate for the population. Several suggestions were made for changing wording and order of questions in order to make it easier to complete. The feedback was adopted and the final survey drafted.

\section{Recruitment and data collection}

The survey instrument was developed for online completion, self-completion, or telephone-interviewer completion. A multipronged recruitment strategy was adopted in order to promote the survey and increase the amount of people who might hear of the study. First, LGBT and mental health organizations, including hospitals and clinics throughout the country, were sent packets with study information $(n=170)$. Each packet contained a letter from the principal investigator inviting organizations to participate in the study by advertising the study through the posters and leaflets that were included in the mailing packet, as well as by making available hardcopies of the questionnaire. Second, LGBT and mental health organizations were sent emails requesting that they pass on the study information and survey link to their email lists. Finally, several major LGBT organizations within Ireland agreed to put details of the study on their Facebook pages.

\section{Ethical considerations}

The study was reviewed and ethical approval to conduct the study was granted by the Research Ethics Committee of the University. At all times, the well-being of respondents was central to the study. Survey respondents were provided with detailed information about the study and issues related to confidentiality and anonymity. It was ensured that respondents' survey responses could in no way be linked to them. Completion of the survey was taken as consent. Respondents were provided with a list of mental health and LGBT support organizations in case they wished to contact them. All data were stored in accordance with the Data Protection (Amendment) Act 2003 (Government of Ireland 2003).

\section{Data analysis}

Survey data were analyzed using the computer program PASW Statistics, version 18.0 (IBM Corporation 2009). Univariate analyses were conducted on all variables to generate descriptives and frequencies. Bivariate analyses were conducted with some variables; however, the majority of response categories were too small to be considered statistically appropriate to include in this paper. The textual data from the open-ended questions were analyzed thematically and the quotes used in the last section of the findings are indicated by the person's preferred sexual orientation and gender identity.

\section{FINDINGS}

\section{Description of the respondent sample}

\section{Demographics}

A total of 156 questionnaires were collected by the closing date of the survey on 31 August 2011. The survey ran for 3 months. Thirty-one of the surveys were removed from the dataset for analysis as a result of the respondent's ineligibility to participate in the study or the survey being incomplete. Consequently, a total of 125 surveys were included for analysis. The ages of respondents in the sample were closely clustered below 45 years: $50 \%$ $(n=62)$ were $25-44$ years of age and $34 \%(n=42)$ were 18-24 years of age. No one in the sample was over 65 years of age. More than $90 \%(n=120)$ of the sample was white Irish or from another white background. Nearly $80 \%(n=96)$ of respondents reported living in a town or city of 5000 people or more. Approximately half of the sample $(53 \%, n=66)$ were working, and an additional $26 \%(n=32)$ were students. Approximately $70 \%(n=87)$ of the sample had completed third level education. In terms of relationship status, $39 \%(n=60)$ were single, $31 \%(n=39)$ in a relationship, and $11 \%(n=11)$ were dating.

\section{Sexual orientation and gender identity}

The breakdown of the sexual orientation and gender identity of the sample is presented in Table 1 . The one respondent who identified as heterosexual was a male who indicated that his gender identity was not the sex assigned to him at birth. Nearly $10 \%(n=12)$ of the sample indicated an 'other' sexual orientation, including 'dyke', 'queer', 'pansexual', 'omnisexual', 'transgender', 'transsexual', and those who did not identify with any particular label. 
TABLE 1: Sexual orientation and gender identity of sample

\begin{tabular}{lc}
\hline Variable $(n=125)$ & $n(\%)$ \\
\hline Sexual orientation & \\
Gay & $52(42)$ \\
Lesbian & $41(33)$ \\
Bisexual & $19(15)$ \\
Heterosexual & $1(0.8)$ \\
Other & $12(10)$ \\
Gender identity & \\
Male & $46(37)$ \\
Female & $68(54)$ \\
Transgender & $3(2)$ \\
Other & $7(6)$ \\
\hline
\end{tabular}

\section{Mental health diagnoses, treatments, services, and provider}

Diagnoses

Approximately three-quarters of the sample $(78 \%, n=97)$ indicated that they had been diagnosed with a mental health issue. People were able to tick multiple response categories. More than half the sample (57\%, $n=72$ ) had been diagnosed with depression, $40 \%(n=50)$ with anxiety, $17 \%(n=21)$ with a sleep disorder, and $14 \%$ $(n=17)$ with an eating disorder. Other diagnoses included bipolar disorder $(8 \%,(n=8)$, schizophrenia $(3 \%, n=3)$, personality disorder $(8 \%, n=8)$, obsessivecompulsive disorder $(8 \%, n=8)$, and post-traumatic stress disorder $(9 \%, n=9)$.

\section{Treatments}

Respondents were asked whether they had received different types of treatments from their mental health provider. More than $60 \%$ of the sample had received psychiatric drugs and an additional $40 \%$ had received cognitive-behavioural therapy. Between $20 \%$ and $30 \%$ of the sample had received psychoanalysis, interpersonal therapy, mindfulness therapy, or art therapy. A further 15 respondents also indicated that they had been offered 'other' treatments, including general counseling services $(n=6)$, talk therapy $(n=2)$, group counseling $(n=2)$, reflective counseling, humanistic and integrative psychotherapy, psychology help, anger management, and hypnotherapy.

\section{Services}

Respondents were also asked about the mental health services they had used. Most people reported using outpatient clinics $(66 \%, n=83)$. Smaller numbers had used inpatient psychiatric hospitals $(22 \%, n=27)$, day hospitals $(14 \%, n=18)$, and day centres $(13 \%, n=16)$.
Last visit to mental health provider

In terms of when respondents reported last seeing a mental health-care provider, $41 \%(n=49)$ had seen a mental health-care provider more than 12 months ago and $15 \%(n=18)$ within the past 7-12 months. A further $16 \%(n=19)$ had seen one in the past $1-3$ months. In terms of the type of mental health-care provider seen, most respondents indicated they had seen a counsellor $(35 \%, n=42)$ or psychiatrist $(29 \%, n=35)$ most recently. Only small percentages had seen a mental-health/ psychiatric nurse, a social worker, or occupational therapist. Of the 'other' mental health providers seen, respondents reported seeing their general practitioner (GP) $(n=5)$, an art therapist, and speaking with a counsellor on the phone.

\section{Experiences with mental health-care provider}

\section{Discussing LGBT identity}

When asked how much they felt they were able to discuss their LGBT identity with their mental health-care provider, $31 \%$ ( $n=37)$ felt they could not discuss their LGBT identity with their mental health provider, while $49 \%$ ( $n=58)$ felt they could. The remaining $20 \%(n=23)$ were unsure. Approximately $20 \%$ of respondents reported that they did not tell their mental health-care provider that they were LGBT, with the remaining $78 \%(n=92)$ indicating that they did. Of those who did tell their mental health-care provider they were LGBT $(n=91), 49 \%$ $(n=45)$ reported that they received a mostly positive reaction, while $41 \%(n=37)$ received a mixed reaction. A smaller number $(10 \%, n=9)$ received a mostly negative reaction.

Respondents were asked how open they were about being LGBT when visiting a mental health professional, whether they feared a negative reaction from a mental health professional if they came out, and whether they felt it was necessary for their mental health-care providers to know they were LGBT. The majority of the sample reported that they were open about being LGBT $(71 \%$, $n=79$ ) and that they felt it was necessary for their mental health professional $(65 \%, n=72)$ to know they were LGBT. However, a significant minority (16\%, $n=17$ ) reported that they would not reveal their LGBT identity for fear of a negative reaction. The full results are presented in Table 2.

\section{Understanding of LGBT needs}

Respondents were also asked how much they felt their mental health-care provider understood any difficulties they had experienced because they are LGBT $(n=95)$. Interestingly, approximately similar proportions 
TABLE 2: Openness about being LGBT with mental health professional

\begin{tabular}{|c|c|c|c|}
\hline & $\begin{array}{c}\text { Strongly agree or } \\
\text { agree, } n(\%)\end{array}$ & $\begin{array}{l}\text { Neither agree nor } \\
\text { disagree, } n(\%)\end{array}$ & $\begin{array}{l}\text { Strongly disagree or } \\
\text { disagree, } n(\%)\end{array}$ \\
\hline $\begin{array}{l}\text { I am generally quite open about being LGBT when I visit } \\
\text { a mental health professional }(n=112)\end{array}$ & $79(71)$ & $14(13)$ & $19(17)$ \\
\hline $\begin{array}{l}\text { I would not reveal my LGBT identity to mental health } \\
\text { professionals for fear of a negative reaction }(n=109)\end{array}$ & $17(16)$ & $20(18)$ & $72(66)$ \\
\hline $\begin{array}{l}\text { I do not feel it is necessary for mental health professionals } \\
\text { to know my LGBT identity }(n=110)\end{array}$ & $15(14)$ & $23(21)$ & $72(65)$ \\
\hline
\end{tabular}

TABLE 3: Positive experiences of mental health services

\begin{tabular}{|c|c|c|c|}
\hline & $\begin{array}{l}\text { Agree somewhat or } \\
\text { completely, } n(\%)\end{array}$ & $\begin{array}{l}\text { Neither agree nor } \\
\text { disagree, } n(\%)\end{array}$ & $\begin{array}{l}\text { Disagree somewhat or } \\
\text { completely, } n(\%)\end{array}$ \\
\hline $\begin{array}{l}\text { I felt fully comfortable using the mental health service as an LGBT } \\
\text { person }(n=109)\end{array}$ & $69(63)$ & $10(9)$ & $30(28)$ \\
\hline I felt fully respected by the mental health service staff $(n=110)$ & $62(56)$ & $20(18)$ & $28(26)$ \\
\hline $\begin{array}{l}\text { The mental health service understood and was sensitive to LGBT } \\
\text { issues }(n=105)\end{array}$ & $49(47)$ & $17(16)$ & $39(37)$ \\
\hline I have trust and confidence in mental health service staff $(n=109)$ & $47(43)$ & $19(17)$ & $43(40)$ \\
\hline $\begin{array}{l}\text { Mental health service staff used inclusive language that showed me } \\
\text { they were aware that some people are LGBT }(n=105)\end{array}$ & $44(42)$ & $19(18)$ & $42(40)$ \\
\hline My partner was acknowledged by mental health service staff $(n=39)$ & $16(41)$ & $6(15)$ & $17(44)$ \\
\hline $\begin{array}{l}\text { I was asked about my experience of coming out and offered support to } \\
\text { help me with this }(n=93)\end{array}$ & $29(31)$ & $13(14)$ & $51(55)$ \\
\hline $\begin{array}{l}\text { I felt the mental health service responded to my specific needs as an } \\
\text { LGBT person. }(n=97)\end{array}$ & $30(31)$ & $25(26)$ & $42(43)$ \\
\hline My partner was involved in my care the way I wanted $(n=34)$ & $10(29)$ & $9(27)$ & $15(44)$ \\
\hline
\end{tabular}

of respondents felt their mental health-care provider either 'very much' or 'completely' understood their difficulties $(38 \%, n=36)$ or only understood very little or not at all $(35 \%, n=33)$ their difficulties.

Respondents were also asked how much they felt their mental health-care provider could meet their needs if they had any issues related to gender identity. Of these respondents $(n=29)$, a significant number $(41 \%, n=12)$ felt their mental health-care provider could only 'very little' or 'not at all' meet their gender identity needs. Just $18 \%(n=20)$ of respondents felt that mental health professionals had sufficient knowledge about LGBT issues, while $64 \%(n=71)$ felt mental health professionals lack knowledge about LGBT issues.

\section{Positive experiences}

Respondents were asked how much they agreed or disagreed with a series of nine statements related to positive experiences of being an LGBT person using mental health services. While roughly $60 \%$ of respondents reported that they felt fully comfortable using the mental health service as an LGBT person, approximately $40 \%$ of respondents $\mathrm{did}$ not feel comfortable with the services. Significantly, twothirds of respondents did not feel the mental health service responded to their specific needs as an LGBT person and an additional $37 \%$ did not feel the mental health service understood or were sensitive to LGBT issues. Specifically, more than half of the respondents were not asked about or offered support in coming out. Regarding partners, while $41 \%$ indicated that their partner was acknowledged by staff and 29\% felt their partner was involved in their care the way they wanted, more than $40 \%$ of respondents indicated that their partner was not acknowledged or involved in their care the way they wanted. Regarding staff in mental health services, just over half of the sample felt fully respected by the mental health service; however, one in four did not. More specifically, while $42 \%$ of the sample felt that staff used inclusive language, an equally large proportion (40\%) did not. In addition, while $43 \%$ felt that they had trust and confidence in mental health staff, an equally large proportion (40\%) did not. Table 3 presents the full results. 
TABLE 4: Negative experience of mental health services

\begin{tabular}{lcc}
\hline & Yes, $n(\%)$ & No, $n(\%)$ \\
\hline An assumption that I was heterosexual $(n=102)$ & $67(66)$ & $26(29)$ \\
A negative reaction when I disclosed my LGBT identity $(n=91)$ & $24(26)$ & $25(34)$ \\
Insensitive or hurtful comments about my LGBT identity $(n=94)$ & $20(22)$ & $20(21)$ \\
Comments that my LGBT identity was caused by some sort of trauma $(n=93)$ & $19(20)$ & $18(19)$ \\
Comments that my LGBT identity was just a phase $(n=94)$ & $12(13)$ & $73(74)$ \\
Comments that my LGBT identity was related to my upbringing $(n=93)$ & $9(9)$ & $74(79)$ \\
Negative comments about my same-sex attraction or relationship $(n=93)$ & $8(9)$ & $5(9)$ \\
Advice that my orientation could be changed to a heterosexual one $(n=92)$ & $86(87)$ \\
Hostile or threatening comments because of my LGBT identity $(n=95)$ & $85(91)$ \\
Advised not to come out to family, friends, or others $(n=93)$ & $53(91)$ \\
Comments that being transgender/gender identity disorder is not normal $(n=58)$ &
\end{tabular}

\section{Negative experiences}

Of the 106 respondents who responded to this section, nearly two in five $(37.7 \%, n=40)$ reported that they had a negative experience with mental health service providers related to their LGBT identity in the past 5 years. Respondents were asked about their specific negative experiences with mental health services. Approximately two-thirds of respondents reported that the mental health services assumed they were heterosexual and nearly $30 \%$ reported that they received a negative reaction when they disclosed their LGBT identity. Between $10 \%$ and $26 \%$ of respondents also indicated that they received a variety of negative comments about their LGBT identity including comments that their LGBT identity was caused by some sort of trauma or related to their upbringing, comments that their LGBT identity was just a phase or not normal, and negative comments about their same-sex attraction or relationship. Small, yet still significant percentages, reported being advised not to come out and being told that their sexual orientation could be changed to a heterosexual one. Table 4 presents further details.

\section{Overall extent mental health services helped making improvements in mental health}

Approximately six in 10 respondents rated the extent that the mental health service helped them make improvements to their mental health as 'fair' or 'good'. An additional $15 \%$ rated their experience as 'very good'. However, more than $20 \%$ of the sample felt that the mental health service did either a 'poor' or 'very poor' job at helping them make improvements to their mental health.

\section{Improving services}

A total of 92 respondents provided at least one suggestion about how mental health services may be improved for LGBT people in Ireland. A further 40 respondents provided additional comments in relation to their experi- ences of mental health services. Several themes emerged from the qualitative data including: promoting accepting and positive staff attitudes; recognizing LGBT identities; providing treatment options; and increasing awareness of LGBT issues.

Promoting accepting and positive staff attitudes Many respondents were critical of their treatment by mental health practitioners and were concerned that important issues that were raised were largely being ignored. Expectations around the creation of a therapeutic environment as well as the attitudes of practitioners are provided by the following responses:

My shrink spent most of our sessions telling me that my illness was because I was gay and if I just accepted I was straight everything would be ok. (Lesbian female.)

Ensure an atmosphere of comfort and acceptance to encourage LGBT people to be completely honest and treat people with dignity and respect. (Gay male.)

Would be really good to talk to someone who understood LGBT issues. Isolation is huge problem. Stress also. You need to be able to talk to someone you can trust. (Lesbian female.)

\section{Recognizing LGBT identities}

In terms of mental health and well-being, identity was often considered unimportant or irrelevant. The pathologizing of LGBT identities was a major concern for some of the respondents:

I've noticed the term 'Borderline Personality Disorder' being applied far too readily to anyone who identifies as LGBT, thus dismissing the validity of the person's sexual orientation (Lesbian female.)

It is coincidence that I identify as LGBT and have used mental health services in the last 5 years. For me the two 
are unrelated and I did not disclose my identity for discussion, as it was not relevant to my mental health problems that brought me to the services. (Bisexual female.)

Some respondents reported important issues related to transgender people and the need for dedicated specialized support for individuals and their families. The potential stressors and concerns around belonging to groups who experience discrimination and social exclusion are highlighted by the following quote:

While mental health professionals were usually willing to read up on issues related to trans people, and many were willing to learn, there was little understanding of: the way many different aspects of one's identity can overlap to cause stress related to social oppression; the fact that trans people face increased risk of violence when we are not 'passing'; the fact that trans people who 'pass' may face other issues due to being an immigrant, being gay/lesbian/ bi/queer ... (Transgender female.)

This person indicated the challenges faced by transgender people who may not 'pass'. Passing refers to a person's ability to be regarded as a member of the sex with which they physically present (Serano 2007).

The significant needs of families and carers have traditionally been an area of neglect within mental health practice. Often, partners and carers experience the emotional impact of the person's distress, as one respondent reported:

I am the partner of a transgender person. I feel this is an incredibly underserved group, both trans people and their partners, and I find it difficult to have my experiences understood by mental health practitioners across the board when it comes to this issue specifically. (Lesbian female.)

\section{Providing treatment options}

Many of the respondents expressed concern about the limited access to talking therapies and the overreliance on prescribed medications. The therapeutic potential of alternative approaches to psychotropic drugs was recognized:

Provide proper therapy instead of just drugs so clients feel more comfortable disclosing issues. (Gay male.)

For some people, accessing services was particularly problematic for people living in rural Ireland with services, if they exist at all, located in the major cities:

Provide more services with trained staff in the LGBT area in other counties besides only Dublin. It's a long distance for me to travel. Train more endocrinologists in other counties for transgender persons, as again there is only one in Dublin. (Transgender female.)
In terms of mental health recovery, wellness planning was mentioned and online support. Some respondents also wanted more time with practitioners and often felt that they were not given enough time and not being listened to:

I found the Psychiatric Services awful. They quiz you for 10 minutes and then prescribe medications. They don't take time to properly diagnose or explain diagnoses or work out a treatment plan beyond messing about with medication dosages. Psychiatrists rotated frequently so no chance to build up a rapport. (Lesbian female.)

Some respondents reported that there were clear financial barriers to accessing appropriate mental health supports, with great limitations in terms of choice:

Mental health services are considered a luxury in our society. Unless you have an extreme condition that requires hospitalization. There is not financial support for medical cardholders. Greater access to counsellors, psychologists, psychotherapists and psychoanalysts is required. (Lesbian female.)

\section{Increasing awareness of LGBT issues}

Several respondents suggested ways in which service providers may raise awareness of LGBT issues and tackle discrimination. These included displaying materials in hospital and clinic waiting areas to 'acknowledge positive responses to LGBT people' such as posters or leaflets as a way of 'communicating acceptance and openness'. One respondent felt that mental health services should 'provide a clear mission statement that is inclusive of LGBT people and appreciates diversity' and that providers need to 'LGBT proof' all policies, forms, and training. Some respondents mentioned mental health practitioners and the need to appreciate diversity and 'in no way assume a person's sexual orientation or gender identity', as well as creating for GPs 'more awareness of LGBT specific issues when referring LGBT people to mental health services'. One person thought that there should be an effort to 'engage in a public relations or advertising campaign to alert LGBT people and the public in general about specific services. Some suggestions in combating the challenges of discrimination included:

Provide inclusion training on LGBT people and issues to all mental health providers as compulsory. (Gay male.)

Educate staff and providers on trans issues and the diversity of transgender experience in particular. (Transgender female.) 


\section{DISCUSSION AND CONCLUSION}

In the current study, a high proportion of respondents had been diagnosed with a mental health problem and the main treatment continues to be psychotropic medication. Talking therapies were rarely offered, despite current government recommendations (Health Service Executive 2009). Nearly one-third of respondents had seen a psychiatrist and a very small proportion of people had been seen other members of the multidisciplinary team such as mental health nurses (Health Service Executive 2012). Two-thirds of respondents felt that mental health services were unable to respond to LGBT mental health needs whilst one-third felt they could not talk to their mental health provider about LGBT issues. A majority of respondents felt that staff assumed they were heterosexual and almost half said their partner was not acknowledged or made to feel involved in the person's care. These findings support the proliferation of heterosexist attitudes evident within health care (Morrison \& Dinkel 2012).

A significant number of respondents felt staff lacked knowledge of LGBT-specific issues, which is comparable to findings reported in other LGBT studies (Mayock et al. 2009). Other pertinent issues were highlighted in the comments section of the study and these included the distinct lack of family and carer supports, particularly to transgender people, poor or inappropriate staff attitudes, lack of staff education and training, and limited access to talking therapies and non-holistic approaches to care.

In terms of mental health nursing practice, a recent Irish report articulated the need for compassionate, competent, and recovery-oriented practitioners working from a value base of equality, respect for diversity, autonomy, and human rights (Health Service Executive 2012). Where recovery and social inclusion initiatives are concerned, key priorities remain in terms of how mental health nurses may help shape and deliver modern, responsive, and holistic mental health services. Highquality care will require ongoing reflection, supervision, and education in relation to sexual orientation and gender-specific issues to ensure sensitivity and safety. Effective care considers people in the context of their gender identity and sexual preferences, as well as the range of other factors that interplay with gender and impact on people's health and well-being. A good example of gender sensitivity guidelines have been produced by the Australian Government that recommend the provision of services that are responsive to the support needs of LGBT people involving a strengths-based approach that addresses individual needs, preferences, and experiences (Department of Health 2011).
In terms of human rights and equality initiatives, the lives of transgender people remains compromised with people clearly articulating experiences of prejudice and discrimination (Higgins et al. 2011, Mayock et al. 2009). In the USA, for example, according to the National Centre for Transgender Equality, despite legislation, people are still threatened and subjected to physical violence in their daily lives with a significant proportion of people attempting suicide (Grant et al. 2011). In line with international guidelines, opportunities exist for training and education initiatives that target knowledge and skills development in relation to LGB and trans-specific issues. Programs should have a fundamental focus on protecting and promoting human rights, tackling prejudice and discrimination whilst appreciating the richness and diversity of individual experiences (Institute of Medicine 2011). Furthermore, there is an urgent need to train mental health nurses to work alongside LGBT people and their families.

In Ireland, recent policy directives have highlighted key challenges in the development of modern and responsive mental health services. The strategic vision states clearly that consumers and carers should be creatively and meaningfully involved at all levels of service planning and delivery. The approach utilized should be inclusive, empowering, and rights based (Government of Ireland 2006). The findings from the study should assist in guiding mental health policy makers in the development of more inclusive and responsive mental health-care provision. Future research should be adequately funded and should involve LGBT people at all stages.

\section{Study strengths and limitations}

The study presents the opinions of LGBT people who have accessed mental health services in Ireland and has given people the opportunity to highlight pertinent issues and share their experiences. The findings are based on a convenience sample of LGBT people and the survey sample size was low in number, thereby limiting the power of statistical testing. Furthermore, the sample does not represent groups such as the travelling community, black ethnic backgrounds, and the older LGBT population. The study may also underrepresent LGBT people in more rural areas and people who are currently staying in psychiatric hospitals or residential care.

\section{ACKNOWLEDGEMENTS}

The authors would like to thank all of the people who kindly took part in the study and the research advisory group. They are also grateful for the financial support 
received from the Gay and Lesbian Equality Network and the Health Service Executive and to Trinity College Dublin for awarding a Postdoctoral Fellowship.

\section{REFERENCES}

Australian Government (2010). National Standards for Mental Health Services: National Mental Health Strategy. Canberra: Commonwealth of Australia. [Cited 31 January 2013]. Available from: URL: http://www.health.gov.au/internet/ main/publishing.nsf/content/DA71C0838BA6411BCA2577 A0001AAC32/\$File/servst10v2.pdf

Burgess, D., Lee, R., Tran, A. \& Van Ryn, M. (2008). Effects of perceived discrimination on mental health and mental health services utilization among gay, lesbian, bisexual and transgender persons. Journal of LGBT Health Research, 3 (4), 1-14.

Central Statistics Office (2006). Census of Population of Ireland 2006. Dublin: Central Statistics Office.

Central Statistics Office (2011). Census of Population of Ireland 2011: Preliminary Results. Dublin: Central Statistics Office.

Chakraborty, A., McManus, S., Brugha, T. S., Bebbington, P. \& King, M. (2011). Mental health of the non-heterosexual population of England. British Journal of Psychiatry, 198 (2), 143-148.

Cochran, S. D., Sullivan, J. G. \& Mays, V. M. (2003). Prevalence of mental disorders, psychological distress, and mental health services use among lesbian, gay, and bisexual adults in the United States. Journal of Consulting and Clinical Psychology, 71 (1), 53-61.

David, S. \& Knight, B. G. (2008). Stress and coping among gay men: Age and ethnic differences. Psychology and Aging, 23 (1), 62-69.

De Gascun, C., Kelly, J., Salter, N., Lucey, J. \& O’Shea, D. (2006). Gender identity disorder. Irish Medical Journal, 99 (5), 146-148.

Department of Health (2011). Service Guidelines on Gender Safety: Promoting A Holistic Approach to Wellbeing. Melbourne: State Government of Victoria. [Cited 31 January 2013]. Available from: URL: http://docs.health.vic.gov.au/ docs/doc/81B991D400F3ACA5CA25790300100797/\$FILE/ service-guidelines-gender-sensitivity-safety.pdf

European Commission (2012). Special Eurobarometer 393: Discrimination in the EU in 2012. Brussels: European Commission.

Flanagan, S. M. \& Hancock, B. (2010). 'Reaching the hard to reach' - Lessons learned from the VCS (voluntary and community Sector). A qualitative study. BMC Health Services Research, 10, 92.

Government of Ireland (2003). Data Protection (Amendment) Act 2003. Dublin: Stationary Office.

Government of Ireland (2006). A Vision for Change: Report of the Expert Group on Mental Health Policy. Dublin: Stationery Office.
Government of Scotland (2006). Rights, Relationships and Recovery: The Report of the National Review of Mental Health Nursing in Scotland. Edinburgh: Scottish Executive.

Grant, J. M., Mottet, L. A. \& Tanis, J. (2011). Injustice at Every Turn: A Report of the National Transgender Discrimination Survey. Washington, DC: National Center For Transgender Equality.

Happell, B. (2008). Determining the effectiveness of mental health services from a consumer perspective: Part 1: Enhancing recovery. International Journal of Mental Health Nursing, 17 (2), 116-122.

Health Service Executive (2009). LGBT Health: Towards Meeting the Health Care Needs of Lesbian, Gay: Bisexual and Transgender People. Dublin: Health Service Executive.

Health Service Executive (2012). A Vision for Psychiatric/ Mental Health Nursing: A Shared Journey for Mental Health Care. Dublin: Health Service Executive.

Higgins, A., Sharek, D., McCann, E., Sheerin, F., Breen, M. \& McCarron, M. (2011). Visible Lives: Identifying the Experiences and Needs of Older Lesbian, Gay, Bisexual and Transgender (LGBT) People in Ireland. Dublin: GLEN and Age and Opportunity.

Hughes, M. (2009). Lesbian and gay people's concerns about ageing and accessing services. Social Work Education, 62 (2), 186-201.

IBM Corporation (2009). PASW Version 18.0. Armonk, NY: IBM Corporation.

Institute of Medicine (2011). The Health of Lesbian, Gay, Bisexual, and Transgender People: Building A Foundation for Better Understanding (Research Brief). Washington, DC: Institute of Medicine.

King, L. A. \& Smith, N. G. (2004). Gay and straight possible selves: Goals, identity, subjective well-being, and personality development. Journal of Personality, 72 (5), 967-994.

King, M., McKeown, E., Warner, J. et al. (2003). Mental health and quality of life of gay men and lesbians in England and Wales: Controlled, cross-sectional study. British Journal of Psychiatry, 183, 552-558.

King, M., Semlyen, J., Tai, S. S. et al. (2008). A systematic review of mental disorder, suicide, and deliberate self harm in lesbian, gay and bisexual people. BMC Psychiatry, 8, 1-70.

Kuyper, L. \& Fokkema, T. (2011). Minority stress and mental health among Dutch LGBs: Examination of differences between sex and sexual orientation. Journal of Counseling Psychology, 58 (2), 222-233.

Maguen, S. \& Shipherd, J. (2010). Suicide risk among transgender individuals. Psychology and Sexuality, 1 (1), 34-43.

Mayock, P., Bryan, A., Carr, N. \& Kitching, C. (2009). Supporting LGBT Lives: A Study of the Mental Health and WellBeing of Lesbian, Gay, Bisexual and Transgender People. Dublin: Gay and Lesbian Equality Network (GLEN) and BeLonG To Youth Service.

Mental Health Commission (2008). A Recovery Approach within the Irish Mental Health Services. A Framework for Development. Dublin: Mental Health Commission. 
Meyer, I. H. (2010). Identity, stress, and resilience in lesbians, gay men, and bisexuals of color. The Counseling Psychologist, 38 (3), 442-454.

Meyer, I. H., Dietrich, J. \& Schwartz, S. (2007). Lifetime prevalence of mental disorders and suicide attempts in diverse lesbian, gay and bisexual populations. American Journal of Public Health, 97 (11), 1-4.

Morrison, S. \& Dinkel, S. (2012). Heterosexism and health care: A concept analysis. Nursing Forum, 47 (2), 123-130.

National Gay and Lesbian Federation (2009). Burning Issues. Dublin: National Gay and Lesbian Federation.
Newcomb, M. E. \& Mustanski, B. (2010). Internalized homophobia and internalizing mental health problems: A meta-analytic review. Clinical Psychology Review, 30 (8), 1019-1029.

Serano, J. (2007). Whipping Girl: A Transsexual Woman on Sexism and the Scapegoating of Femininity. New York: Seal Press.

UK Department of Trade and Industry (2003). Amendment to Employment Equality (Sexual Orientation) Regulations: Full Regulatory Impact Assessment 2003. London: Stationary Office. 